\title{
Experimental Study on Crack Width of Reinforced HSC-on-SFRFLC Superposed Beams
}

\author{
LI Changyong ${ }^{a}$, CHEN Zhaofei $^{b}$, DING Xinxin ${ }^{c}$ and ZHAO Shunbo ${ }^{d}$
}

School of Civil Engineering and Communication, North China University of Water Resources and Electric Power, Zhengzhou 450011, China

alichang@ncwu.edu.cn, b1103304085@qq.com, cdingxinxin1978@126.com,

'sbzhao@ncwu.edu.cn

Keywords: superposed beam; steel fiber reinforced full-lightweight concrete (SFRFLC); high-strength concrete (HSC); longitudinal tensile reinforcement ratio; fraction of steel fiber by volume; depth of normal section; crack distribution; crack width.

Abstract. To take full advantages of high-strength concrete (HSC) and steel fiber reinforced full-lightweight concrete (SFRFLC), a new type of composite beams was suggested, which was cast by HSC superposed on SFRFLC in certain relative depths. Based on the tests of 13 reinforced HSC (in strength grades of C60 and C70)-on-SFRFLC (in strength grades of LC30) superposed beams comparing with 4 reinforced concrete beams, and by using the crack pattern classification analyzing method, this paper studies the regularity of main cross-sectional crack distribution affected by the longitudinal tensile reinforcement ratio, the fraction of steel fiber by volume and the sectional depth of SFRFLC. The methods are determined for the calculation of the height of effective tensile cracked area and the stress of longitudinal tensile rebar considering the loading performance of SFRFLC. The formulas for calculating the crack space and crack width of reinforced HSC-on-SFRFLC superposed beams are suggested.

\section{Introduction}

Concrete is the largest amount of building materials in modern civil engineering, and concrete structure is also the main type of structures. However, ordinary concrete and its structure has the disadvantage of heavy self-weight. Adopting the lightweight aggregate concrete with light self-weight and good thermal insulation properties to lighten the structural weight is a rational direction of development for green building [1, 2]. Adopting the steel fiber reinforced full-lightweight concrete (SFRFLC) to enhance the structural cracking-resistance of tensile zone and restrain the elongation of crack width for the purpose of increasing the structural ductility and durability, is also an optimal target of structural materials [3-7]. Therefore, the authors of this paper suggested a new type beam-slab composite structure, superposed beam which is composited by upper high-strength concrete (HSC) on bottom SFRFLC in certain depths to take full advantage of HSC with good compressive properties and SFRFLC with good tensile performance [8]. Combining a series of experimental results of cracks at normal sections of superposed beams [9, 10], the paper analyzes the distribution of crack width and the influence factors, and proposes the calculation method for crack width of superposed beams.

\section{Experimental}

There were 17 test beams with section $b \times h=150 \mathrm{~mm} \times 300 \mathrm{~mm}, 3 \mathrm{~m}$ long and $2.7 \mathrm{~m}$ span-length. The strength grades of HSC were C60 and C70, the strength grade of SFRFLC was LC30. The longitudinal tensile reinforcements were HRB400 ribbed bar in diameter of $14 \mathrm{~mm}$ and $18 \mathrm{~mm}$, and HRB335 ribbed bar in diameter of $20 \mathrm{~mm}, 22 \mathrm{~mm}$ and $25 \mathrm{~mm}$. The thickness of concrete cover was 25 $\mathrm{mm}$. The steel fiber was steel thin-plate sheared with end-hooks, $32 \mathrm{~mm}$ long and $0.6 \mathrm{~mm}$ equivalent diameter. 
The measured properties of test beams are listed in Table 1. The content of beam No. is strength grade of concrete-sectional depth of SFRFLC-diameter of longitudinal tensile rebar-fraction of steel fiber by volume, $a$ and $b$ express 2 beams in a group.

The test device was built by counter-force frame and hydraulic jacks, the beam was simply supported under symmetric concentrated loads on the two-points at mid-span, the loads were controlled by the load transducer. The crack width after cracking of cross-sectional concrete was measured by reading microscope.

Table 1 Properties of test beams

\begin{tabular}{|c|c|c|c|c|c|c|c|c|c|}
\hline \multirow{2}{*}{ Beam No. } & \multicolumn{3}{|c|}{ Strength of HSC [MPa] } & \multicolumn{3}{|c|}{ Strength of SFRFLC [MPa] } & \multirow{2}{*}{$\begin{array}{l}\text { Longitudinal } \\
\text { tensile rebars }\end{array}$} & \multirow{2}{*}{$\begin{array}{c}\rho_{\mathrm{f}} \\
{[\%]}\end{array}$} & \multirow{2}{*}{$\begin{array}{c}h_{1} \\
{[\mathrm{~mm}]}\end{array}$} \\
\hline & $\overline{f_{\mathrm{cu}}}$ & $f_{\mathrm{c}}$ & $f_{\mathrm{t}}$ & $\overline{f_{\text {fcu }}}$ & $f_{\text {fc }}$ & $f_{\mathrm{ft}}$ & & & \\
\hline C60-0-18-0a & 69.0 & 55.4 & 4.32 & - & - & - & $2 \Phi 18$ & 0 & 0 \\
\hline C60-0-18-0b & 69.0 & 55.4 & 4.32 & - & - & - & $2 \Phi 18$ & 0 & 0 \\
\hline C60-230-18-1.2a & 69.0 & 55.4 & 4.32 & 41.1 & 37.2 & 3.25 & $2 \Phi 18$ & 1.2 & 230 \\
\hline $\begin{array}{c}\mathrm{C} 60-230-18-1.2 \\
\mathrm{~b}\end{array}$ & 69.0 & 55.4 & 4.32 & 41.1 & 37.2 & 3.25 & $2 \Phi 18$ & 1.2 & 230 \\
\hline C70-0-18-0a & 81.1 & 65.6 & 4.63 & - & - & - & $2 \Phi 18$ & 0 & 0 \\
\hline C70-0-18-0b & 81.1 & 65.6 & 4.63 & - & - & 一 & $2 \Phi 18$ & 0 & 0 \\
\hline C70-240-18-0.8a & 82.3 & 65.8 & 4.80 & 42.4 & 38.1 & 3.18 & $2 \Phi 18$ & 0.8 & 240 \\
\hline C70-240-18-1.2a & 82.3 & 65.8 & 4.80 & 43.6 & 38.9 & 3.49 & $2 \Phi 18$ & 1.2 & 240 \\
\hline $\begin{array}{c}\mathrm{C} 70-240-18-1.2 \\
\mathrm{~b}\end{array}$ & 82.3 & 65.8 & 4.80 & 43.6 & 38.9 & 3.49 & $2 \Phi 18$ & 1.2 & 240 \\
\hline C70-240-18-1.6a & 82.3 & 65.8 & 4.80 & 44.2 & 39.6 & 4.18 & $2 \Phi 18$ & 1.6 & 240 \\
\hline C70-260-14-1.2a & 80.8 & 65.0 & 4.70 & 42.4 & 38.9 & 3.38 & $2 \Phi 14$ & 1.2 & 260 \\
\hline $\begin{array}{c}\mathrm{C} 70-260-14-1.2 \\
\mathrm{~b}\end{array}$ & 80.8 & 65.0 & 4.70 & 42.4 & 38.9 & 3.38 & $2 \Phi 14$ & 1.2 & 260 \\
\hline C70-230-20-1.2a & 80.8 & 65.0 & 4.70 & 42.4 & 38.9 & 3.38 & $2 \Phi 20$ & 1.2 & 230 \\
\hline $\begin{array}{c}\mathrm{C} 70-230-20-1.2 \\
\mathrm{~b}\end{array}$ & 80.8 & 65.0 & 4.70 & 42.4 & 38.9 & 3.38 & $2 \Phi 20$ & 1.2 & 230 \\
\hline C70-220-22-1.2a & 80.8 & 65.0 & 4.70 & 42.4 & 38.9 & 3.38 & $2 \Phi 22$ & 1.2 & 220 \\
\hline $\begin{array}{c}\mathrm{C} 70-220-22-1.2 \\
\mathrm{~b}\end{array}$ & 80.8 & 65.0 & 4.70 & 42.4 & 38.9 & 3.38 & $2 \Phi 22$ & 1.2 & 220 \\
\hline C70-210-25-1.2a & 81.6 & 65.2 & 4.67 & 43.0 & 39.2 & 3.46 & $2 \Phi 25$ & 1.2 & 210 \\
\hline
\end{tabular}

\section{Analyses of Test Results}

Characteristics of Crack Distribution. The distribution of crack on side surface in pure bending segment of some test beams under normal service loads are shown in Fig. 1, the numbers are the ratios of moment $M$ to ultimate moment $M_{\mathrm{u}}$ corresponding to the crack elongation to those points. It can be seen that, comparing with the larger space and higher elongation of cracks in the similar $M / M_{\mathrm{u}}$ of the ordinary reinforced concrete beams, the cracks of superposed beams were closer and smaller in space, lower depth in elongation with secondary and rhizoid states. When the load was lower than $40 \%$ ultimate load, the elongation of cracks on superposed beams was slower than that of cracks on ordinary reinforced beams. When the load was over $40 \%$ ultimate load, the space and elongation of cracks trended to be steady.

Statistical Analysis of Crack Patterns. During the loading procedure, cracks with different patterns appeared on test beams. Only the crack continuously elongation or fastly up to neutral axis under loads after initial cracking belonging to the main crack (i.e. a-crack), which took the control effect on the total development and distribution of cracks on superposed beams [11]. Those cracks without changes along with load actions appeared due to the defact of concrete, the stress concentration with tensile rebar or the restraining by longitudinal tensile rebars, which had little effect on the main crack distribution. Referencing the classification method of crack patterns for reinforced concrete beams $[11,12]$, the statistical analysis results of average crack space, average crack width and maximum crack width of a-cracks on superposed beams under normal service loads $\left(M / M_{\mathrm{u}}=0.45 \sim 0.65\right)$ are listed in Table 2. 
From the test data in Table 2, the SFRFLC in bottom zone of superposed beams directly increased the cracking resistance, in which the steel fibers bridging crack sections to link the cracked concrete and transfering the tensile stress to uncracked sections, the final apparence was the decreases of crack space and width due to the fast concentration within short space to reach the peak value. Comparing the crack distribution and elongation of series C70-240-18-**, with the increase of the fraction of steel fiber by volume, the increased bridging effect of steel fibers led the adding of numbers of secondary cracks which made the obvious reduce of a-cracks due to the repeatedly unloading effect. The strength enhancement of upper HSC and the depth change of bottom SFRFLC affected little on the distribution and elongation of a-cracks of superposed beams.

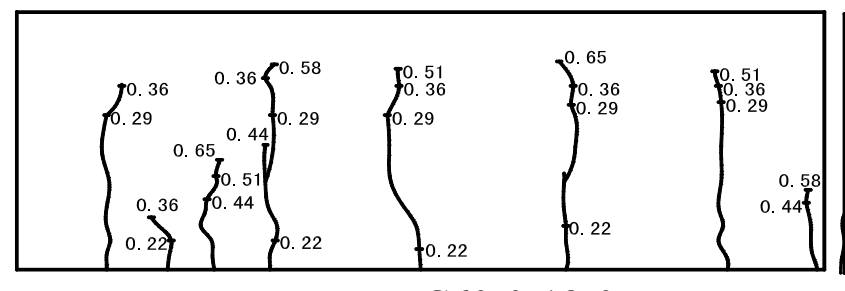

C60-0-18-0a

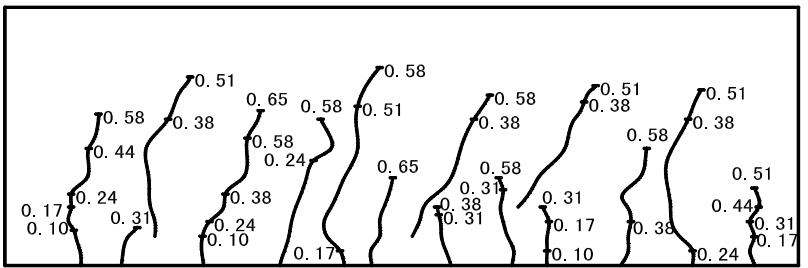

C60-230-18-1.2a

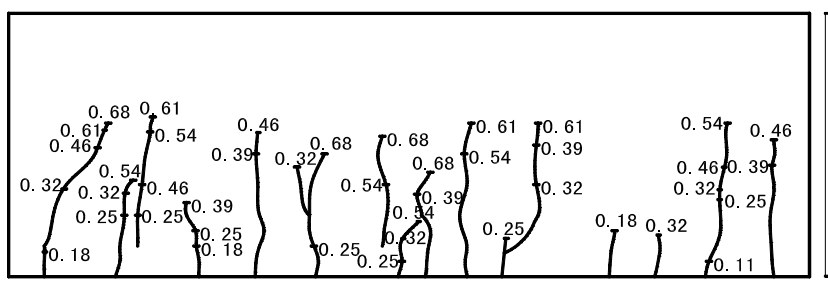

C70-230-20-1.2a

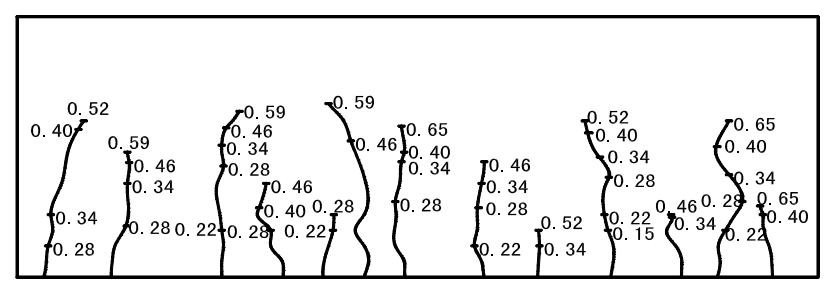

C70-220-22-1.2a

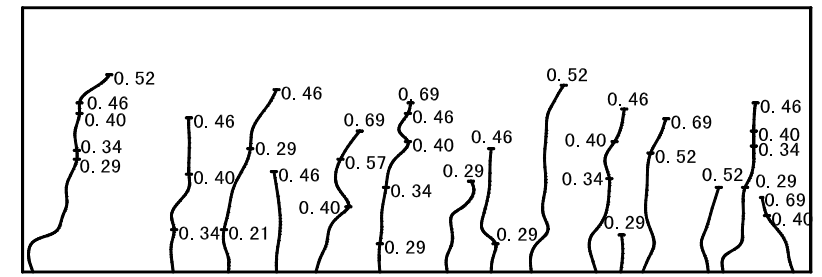

C70-260-14-1.2a

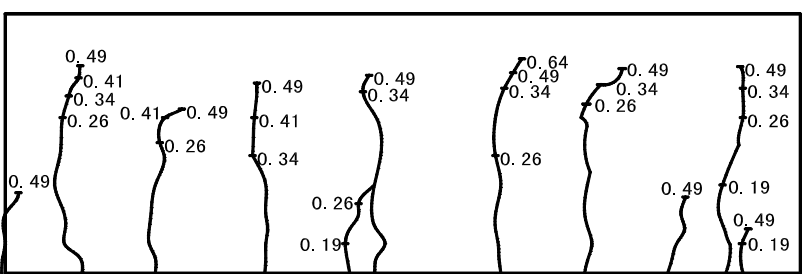

C70-0-18-0a

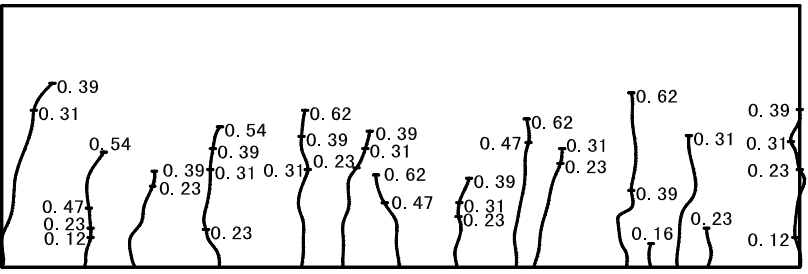

C70-240-18-0.8a

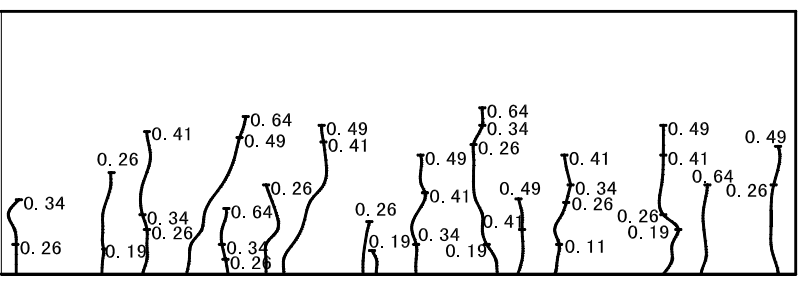

C70-240-18-1.2a

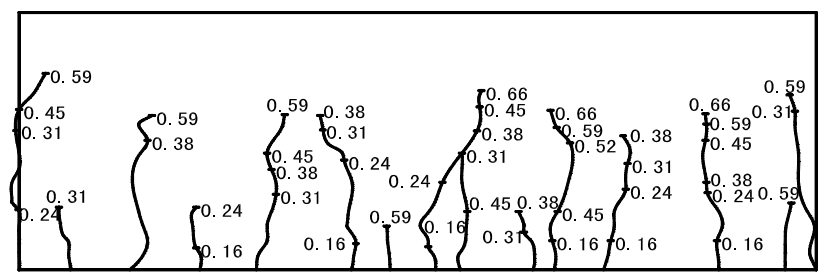

C70-240-18-1.6a

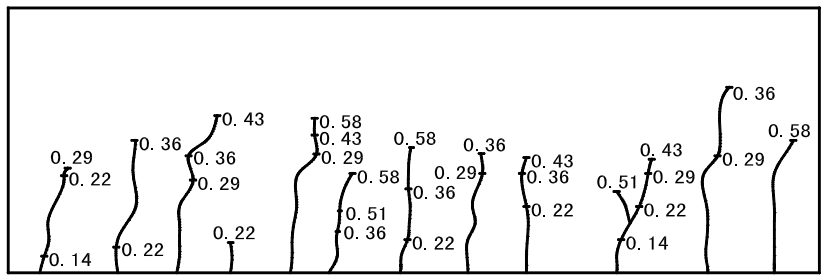

C70-210-25-1.2a

Figure 2. Crack distribution of test beams under normal service loading 


\section{Calculation of Crack Width}

Average Crack Space. Based on the formula for reinforced concrete beam [11]

$$
l_{\text {cr }}=k_{1} c_{\mathrm{s}}+k_{2} \frac{d}{\rho_{\mathrm{te}}} \cdot \frac{h}{a_{\mathrm{s}}} .
$$

Where, $h$ is the sectional depth; $a_{\mathrm{s}}$ is the distance of cross-sectional center of all longitudinal tensile rebars to tensile edge of cross-section of beam; $\rho_{\text {te }}$ is the effective reinforcement ratio of longitudinal tensile rebars, $\rho_{\mathrm{te}}=A_{\mathrm{s}} / A_{\text {te }}$, which should be taken as 0.01 when $\rho_{\mathrm{te}} \leq 0.01 ; A_{\mathrm{s}}$ is the cross-sectional area of longitudinal tensile rebars; $A_{\text {te }}$ is the effective tensile area of crack section, $A_{\text {te }}=b \times h_{\text {te }}$.

Table 2 Test data of mean crack spacing, mean crack width and maximum crack width

\begin{tabular}{|c|c|c|c|c|c|c|c|c|c|}
\hline Beam No. & $\begin{array}{c}l_{\text {cr }} \\
(\mathrm{mm})\end{array}$ & $\begin{array}{c}M \\
(\mathrm{kN} . \mathrm{m})\end{array}$ & $\begin{array}{c}w_{\mathrm{cr}} \\
(\mathrm{mm})\end{array}$ & $\begin{array}{c}w_{\max } \\
(\mathrm{mm})\end{array}$ & Beam No. & $\begin{array}{c}l_{\mathrm{cr}} \\
(\mathrm{mm})\end{array}$ & $\begin{array}{c}M \\
(\mathrm{kN} \cdot \mathrm{m})\end{array}$ & $\begin{array}{c}\left.\begin{array}{c}w_{\mathrm{cr}} \\
(\mathrm{mm})\end{array}\right)\end{array}$ & $\begin{array}{c}w_{\max } \\
(\mathrm{mm})\end{array}$ \\
\hline \multirow[t]{4}{*}{ C60-0-18-0a } & 136. & 31.5 & 0.12 & 0.20 & \multirow[t]{4}{*}{ C60-0-18-0b } & 124. & 27.0 & 0.08 & 0.11 \\
\hline & 0 & 36.0 & 0.14 & 0.22 & & \multirow[t]{3}{*}{0} & 31.5 & 0.10 & 0.15 \\
\hline & & 40.5 & 0.18 & 0.26 & & & 36.0 & 0.11 & 0.15 \\
\hline & & 45.0 & 0.19 & 0.27 & & & 40.5 & 0.13 & 0.20 \\
\hline \multirow[t]{4}{*}{ C60-230-18-1.2a } & 76.8 & 33.75 & 0.05 & 0.07 & \multirow{4}{*}{$\begin{array}{c}\mathrm{C} 60-230-18-1.2 \\
\mathrm{~b}\end{array}$} & \multirow[t]{4}{*}{80.8} & 29.25 & 0.04 & 0.08 \\
\hline & & 38.25 & 0.06 & 0.08 & & & 33.75 & 0.05 & 0.07 \\
\hline & & 42.75 & 0.06 & 0.09 & & & 38.25 & 0.06 & 0.07 \\
\hline & & 47.25 & 0.06 & 0.08 & & & 42.75 & 0.06 & 0.08 \\
\hline \multirow[t]{4}{*}{ C70-0-18-0a } & 126. & 29.25 & 0.09 & 0.13 & \multirow[t]{4}{*}{ C70-0-18-0b } & 125. & 29.25 & 0.11 & 0.14 \\
\hline & 0 & 33.75 & 0.10 & 0.16 & & \multirow[t]{3}{*}{0} & 33.75 & 0.12 & 0.16 \\
\hline & & 38.25 & 0.12 & 0.17 & & & 38.25 & 0.15 & 0.18 \\
\hline & & 42.75 & 0.13 & 0.18 & & & 42.75 & 0.17 & 0.22 \\
\hline \multirow[t]{4}{*}{ C70-240-18-0.8a } & 74.6 & 27.0 & 0.04 & 0.07 & \multirow[t]{4}{*}{ C70-240-18-1.2a } & \multirow[t]{4}{*}{95.0} & 29.25 & 0.05 & 0.08 \\
\hline & & 31.5 & 0.05 & 0.08 & & & 33.75 & 0.05 & 0.09 \\
\hline & & 36.0 & 0.06 & 0.09 & & & 38.25 & 0.06 & 0.12 \\
\hline & & 40.5 & 0.06 & 0.10 & & & 42.75 & 0.07 & 0.15 \\
\hline \multirow{4}{*}{$\begin{array}{c}\mathrm{C} 70-240-18-1.2 \\
\mathrm{~b}\end{array}$} & 95.0 & 29.25 & 0.05 & 0.12 & \multirow[t]{4}{*}{ C70-240-18-1.6a } & \multirow{4}{*}{$\begin{array}{r}112 . \\
0\end{array}$} & 33.75 & 0.04 & 0.07 \\
\hline & & 33.75 & 0.06 & 0.14 & & & 38.25 & 0.04 & 0.07 \\
\hline & & 38.25 & 0.06 & 0.18 & & & 42.75 & 0.05 & 0.09 \\
\hline & & 42.75 & 0.08 & 0.19 & & & 47.25 & 0.06 & 0.10 \\
\hline \multirow[t]{5}{*}{ C70-260-14-1.2a } & 90.0 & 20.25 & 0.05 & 0.10 & \multirow{5}{*}{$\begin{array}{c}\mathrm{C} 70-260-14-1.2 \\
\mathrm{~b}\end{array}$} & \multirow{5}{*}{$\begin{array}{r}101 . \\
0\end{array}$} & 20.25 & 0.04 & 0.09 \\
\hline & & 22.50 & 0.06 & 0.10 & & & 22.50 & 0.05 & 0.12 \\
\hline & & 24.75 & 0.06 & 0.09 & & & 24.75 & 0.06 & 0.13 \\
\hline & & 27.00 & 0.07 & 0.10 & & & 27.00 & 0.07 & 0.14 \\
\hline & & 29.25 & 0.07 & 0.12 & & & 29.25 & 0.07 & 0.15 \\
\hline \multirow[t]{4}{*}{ C70-230-20-1.2a } & 81.7 & 33.75 & 0.04 & 0.06 & \multirow{4}{*}{$\begin{array}{c}\mathrm{C} 70-230-20-1.2 \\
\mathrm{~b}\end{array}$} & \multirow[t]{4}{*}{78.6} & 29.25 & 0.04 & 0.06 \\
\hline & & 38.25 & 0.05 & 0.08 & & & 33.75 & 0.05 & 0.06 \\
\hline & & 42.75 & 0.05 & 0.09 & & & 38.25 & 0.06 & 0.08 \\
\hline & & 47.25 & 0.06 & 0.06 & & & 42.75 & 0.06 & 0.10 \\
\hline \multirow[t]{4}{*}{ C70-220-22-1.2a } & 90.0 & 38.25 & 0.04 & 0.06 & \multirow{4}{*}{$\begin{array}{c}\mathrm{C} 70-220-22-1.2 \\
\mathrm{~b}\end{array}$} & \multirow[t]{4}{*}{84.1} & 38.25 & 0.04 & 0.08 \\
\hline & & 42.75 & 0.05 & 0.07 & & & 42.75 & 0.06 & 0.10 \\
\hline & & 47.25 & 0.05 & 0.07 & & & 47.25 & 0.06 & 0.10 \\
\hline & & 51.75 & 0.06 & 0.08 & & & 51.75 & 0.07 & 0.14 \\
\hline \multirow[t]{2}{*}{ C70-210-25-1.2a } & 80.5 & 47.25 & 0.05 & 0.09 & \multirow[t]{2}{*}{ C70-210-25-1.2a } & 80.5 & 60.75 & 0.07 & 0.13 \\
\hline & & 54.00 & 0.06 & 0.11 & & & 67.50 & 0.08 & 0.14 \\
\hline
\end{tabular}

Fig. 2 shows the change of a-crack width along cross-sectional depth of test beams. The crack had maximum width at the bottom of beam and decreased near the center of longitudinal tensile rebars; with the distance far from the center of longitudinal tensile rebars, the crack width reduced little by little after increased a certain width at the web of beam. This basically reflected the depth's change of effective tensile area. Therefore, considering that the enhancement of SFRFLC on tensile zone 
decreases the depth of effective tensile area of superposed beam, the formula on the basis of statistical analysis is

$$
\begin{aligned}
& h_{\mathrm{fte}}=h_{\mathrm{te}}\left(1-0.78 \lambda_{\mathrm{f}}\right) . \\
& h_{\mathrm{te}}=c_{\mathrm{s}}+(n-1) s+(5+n) d .
\end{aligned}
$$

Where, $h_{\mathrm{fte}}$ is the depth of effective tensile area of superposed beam; $h_{\mathrm{te}}$ is the depth of effective tensile area of ordinary reinforced concrete beam; $\lambda_{\mathrm{f}}$ is the characteristic value of steel fiber; $c_{\mathrm{s}}$ is the thickness of concrete cover of longitudinal tensile rebar at the outermost layer, take $c_{\mathrm{s}}=5 d$ while $c_{\mathrm{s}} \geq 5 d$; $d$ is the diameter of longitudinal tensile rebar; $n$ is the number of rows of longitudinal tensile rebar; $s$ is the clear distance between upper and lower rows.
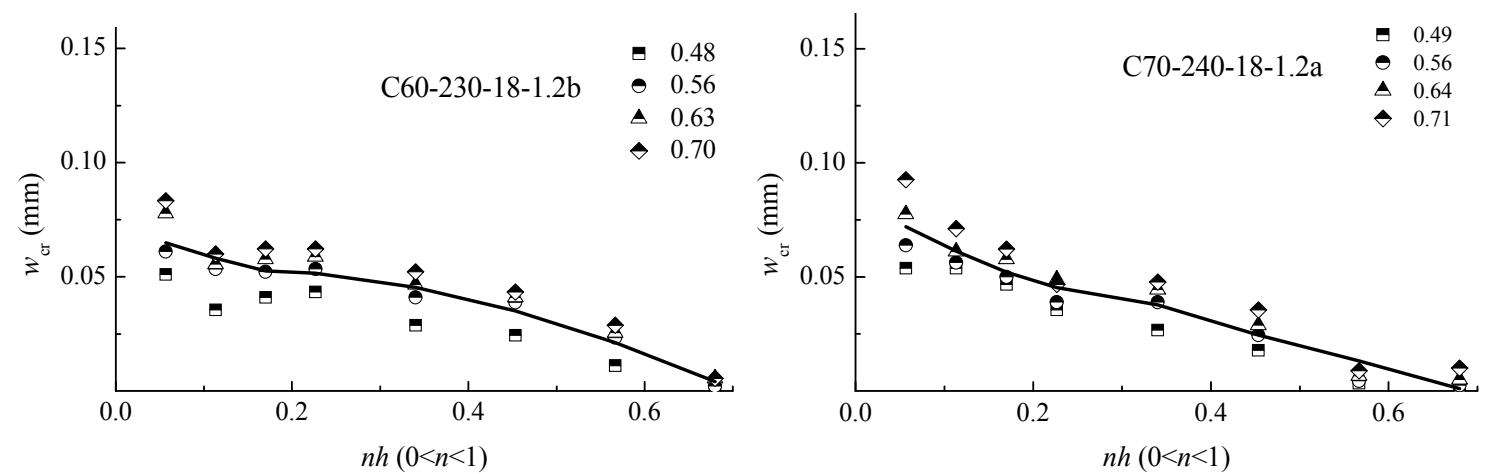

Figure 2. Change of crack width along cross-sectional depth of test beams

Therefore, the effective reinforcement ratio of longitudinal tensile rebar is

$$
\rho_{\mathrm{fte}}=\rho_{\mathrm{te}} /\left(1-0.78 \lambda_{\mathrm{f}}\right) \text {. }
$$

Based on the statistical analysis of crack patterns, introducing the influence factor $1 /\left(1-\beta_{\mathrm{cs}} \lambda_{\mathrm{f}}\right)$ to reflect the effect of $c_{\mathrm{s}}$ on $l_{\text {fcr }}$ (here, $\beta_{\mathrm{cs}}$ is the coefficient due to adding of steel fiber), and overlooking the influence of beam's depth, the formula of average crack space of superposed beam is

$$
l_{c r}=\frac{1.9 c_{s}}{1-0.18 \lambda_{\mathrm{f}}}+0.087\left(1-0.78 \lambda_{\mathrm{f}}\right) \frac{d}{\rho_{t e}} .
$$

The formula (5) will be deduced to the formula of ordinary reinforced concrete beam when $\lambda_{\mathrm{f}}=0$ $[11,12]$, which shows that the steel fiber increases the effect of concrete cover on crack space, but reduces the effect of longitudinal tensile rabar on crack space.

The mean ratio of test $l_{\text {fcr }}{ }^{t}$ to calculated $l_{\text {fcr }}{ }^{\mathrm{c}}$ of test beams is 1.044 with standard deviation of 0.161 .

Crack Width. The maximum and average width of cracks can be calculated with formulas

$$
\begin{aligned}
& w_{\text {max }}=\tau_{\mathrm{s}} w_{\mathrm{m}} . \\
& w_{\mathrm{m}}=\alpha_{\mathrm{c}} \psi \frac{\sigma_{\mathrm{s}}}{E_{\mathrm{s}}} l_{\mathrm{cr}} .
\end{aligned}
$$

Where, $\tau_{\mathrm{s}}$ is the enlargement coefficient of average width of cracks; $\psi$ is the strain nonuniform coefficient of longitudinal tensile rebar among cracks, $\psi=1-0.5 f_{\mathrm{t}} /\left(\rho_{\mathrm{te}} \sigma_{\mathrm{s}}\right) ; \sigma_{\mathrm{s}}$ is the tensile stress of longitudinal tensile rebar; $E_{\mathrm{s}}$ is the elastic modulus of longitudinal tensile rebar; $\alpha_{\mathrm{c}}$ is the coefficient due to the influence of concrete deformation among cracks, take as $0.7 ; f_{\mathrm{t}}$ is the tensile strength of concrete.

The statistical analysis of a-cracks distribution gives that $\tau_{\mathrm{s}}=1.53$ considering reliability of $95 \%$.

Compared with the ordinary reinforced concrete beam, the superposed beam has larger effective reinforcement ratio and the steel fibers bridging cracks share the tensile stress of rebar. Therefore, the 
tensile capacity of SFRFLC was considered when the equilibrium fundamental equations were established [9]. After reasonably simplified, the formula is

$$
\sigma_{\mathrm{s}}=\frac{M}{0.87 h_{0} A_{\mathrm{s}}}-\frac{2 f_{\mathrm{ft}} b a_{\mathrm{s}}}{A_{\mathrm{s}}} \text {. }
$$

Where, $M$ is the bending moment on cross-section under normal service load; $b$ and $h_{0}$ are the width and effective depth of cross-section, respectively, $h_{0}=h-a_{\mathrm{s}}$.

The mean ratio of test $w_{\mathrm{m}}{ }^{\mathrm{t}}$ to calculated $w_{\mathrm{m}}{ }^{\mathrm{c}}$ of test beams is 1.013 with standard deviation of 0.201 . The mean ratio of test $w_{\max }{ }^{\mathrm{t}}$ to calculated $w_{\max }{ }^{\mathrm{c}}$ of test beams is 1.138 with standard deviation of 0.260 .

\section{Summary}

Compared with the reinforced concrete beam in the same condition, the cracks distribute on superposed beam as smaller space, short elongation, more secondary and rhizoid states. Based on the test data and adopting statistical analysis of crack patterns, the statistical results of the average space, average width and maximum width of main cracks on the superposed beam were given out.

The strength grade of HSC and the depth of SFRFLC influenced little on the crack distribution and elongation. The effects of concrete cover and reinforcement on cracks and tensile stress of rebar were all comprehensively affected by the steel fiber.

Formulas for the calculation of crack width of the superposed beam are proposed considering the tensile performance of SFRFLC.

\section{Acknowledgements}

This work was financially supported by the Key Research Project of Science and Technology of the Department of Education, Henan Province (14B560004, 12A560008), Scientific and Technological Innovation Team on Eco-building Materials and Structural Engineering in Universities of Henan Province (13IRTSHN002).

\section{References}

[1] Cui JH: Civil Engineering and China Development (China WaterPower Press, Beijing 2015).

[2] Zhao SB: Design Principles of Concrete Structures, 2nd Edition (Tongji University Press, Shanghai 2013)

[3] Li CY, Zhao MS, Chen YL and Ding XX: Experimental study on basic properties of high-strength full-lightweight concrete. Journal of Henan University (Natural Science), 2014, 44(6): 749-752.

[4] Pan LY, Xu WX, Chen YL and Li CY: Experimental study on the basic properties of full-lightweight concrete. Journal of North China University of Water Resources and Electric Power (Natural Science Edition), 2015, 36(2): 7-10.

[5] Zhao SB, Li CY and Qian XJ: Experimental study on mechanical properties of steel fiber reinforced full lightweight concrete. Geotechnical Special Publication No.212 CASCE 2011, pp. 233-239

[6] Pan LY, Yuan H and Zhao SB: Experimental study on early-age cracking-resistance of hybrid fiber reinforced full-lightweight concrete. Water Power, 2011, 37(9): 95-97.

[7] Zhang XY, Li CY, Yuan H and Pan LY: Experimental study on flexural toughness of hybrid fiber reinforced full-lightweight concrete. Water Power, 2013, 39(5): 87-89. 
[8] Zhao SB, Li CY and Li XK: One type superposed beam with steel fiber reinforced lightweight concrete and high-strength concrete (China Patent: ZL201220274599.4, 2012).

[9] Pan LY, Shang YQ, Kang XX and Li CY: Experimental study on flexural stiffness of steel fiber reinforced full-lightweight concrete superposed beams. Journal of North China University of Water Resources and Electric Power (Natural Science Edition), 2015, 36(1): 43-46.

[10] Zhao SB, Guan JF and Zhang XP: Experimental study and statistical analysis of crack pattern of reinforced concrete beams. Engineering Mechanics, 2008, 25(12): 141-146.

[11] Zhao SB, Guan JF and Li XK: Simulation Test and Optimal Design of Reinforced Concrete Structures (China WaterPower Press, Beijing 2011). 